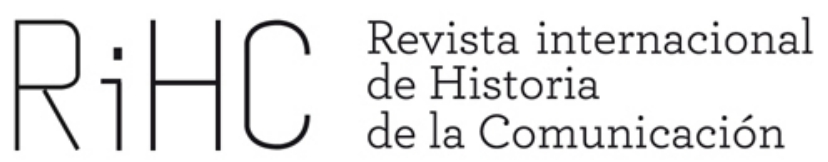

\title{
DOS ACTOS FUNDACIONALES PARA LOS NUEVOS MOVIMIENTOS SOCIALES: EZLN Y LA BATALLA DE SEATTLE
}

DOI: http://dx.doi.org/10.12795/RiHC.2017.i08.05

\author{
Javier Antonio Enríquez Román \\ Universidad Complutense de Madrid \\ jenrique@ucm.es
}

aceptado: $23-11-2016$

recibido: $11-3-2017$

Resumen: El estudio de los movimientos sociales presenta un punto de inflexión a partir de dos acontecimientos capitales en la Historia del siglo XX. Primero, la caída del Muro de Berlín, en 1989, y la posterior desaparición de los regímenes comunistas en la Unión Soviética y sus Estados satélites en Europa del Este, con el consiguiente desarrollo del sistema capitalista por todo el planeta, encontrando en el neoliberalismo su última fase de desarrollo. $Y$, segundo, la irrupción de Internet, generalizada social $e$ institucionalmente a partir de los años noventa, lo que proporciona a los activistas una herramienta fantástica. La Red, unida al espectacular desarrollo de las nuevas tecnologías de la información y comunicación (TICS) como los teléfonos móviles o las pequeñas cámaras de video, impulsa una profunda revolución en los movimientos sociales, capaces de emplear Internet para difundir todo tipo de información sin necesidad de los medios de comunicación tradicionales; promover y fomentar la creación de redes de solidaridad transnacionales; y coordinar actividades entre activistas y simpatizantes, de carácter local. El Ejercito Zapatista de Liberación Nacional 
(EZLN), de inspiración zapatista, fue el primer movimiento social en emplear Internet para transformar un insignificante levantamiento armado en una (casi) desconocida región de México (Chiapas, 1994) en un movimiento de resistencia global, frente al neoliberalismo. Junto a la contra-cumbre de Seattle, primera gran manifestación organizada y coordinada por Internet, donde más de 50.000 activistas hicieron fracasar la Cumbre de la Organización Mundial del Comercio (Seattle, Estados Unidos, 1999), son episodios "fundacionales" de lo que, a partir de entonces, debemos llamar nuevos movimientos sociales.

Palabras clave: Movimientos sociales; zapatismo; EZLN; internet, comunicación; antiglobalización.

\begin{abstract}
The study of social movements reaches a turning point with two important events in 20th century history. First, the fall of the Berlin wall in 1989 and the disappearance of communist regimes in USSR and its satellite states in eastern Europe. This meant the further development of capitalism all over the world, being neoliberalism the final stage. Second, the emergence of Internet, widespread in the nineties, a fantastic tool for activists. This fact, together with the spectacular development of new Information and Communications Technology (ICT) such as mobile phones or small video cameras, drove a deep revolution (and evolution) in social movements. They were able to use the net to spread all kind of information without traditional mass media, promote the creation of transnational solidarity networks and coordinate local activities between activists and sympathizers. The Zapatista National Liberation Army (EZLN), inspired by Zapata, was the first social movement to use the net to transform an insignificant armed uprising in a (almost unknown) region of Mexico (Chiapas, 1994) in a global and international resistance movement opposed to neoliberalism. This fact, together with the Seattle WTO protest, the first one organized and coordinated using the Internet where more than 50000 activists disrupted a WTO summit (Seattle, United States, 1999), are the foundation of what we call new social movements.
\end{abstract}

Keywords: Social movements; zapatismo; EZLN; internet; communication; antiglobalization.

\title{
1 Introducción
}

Los movimientos sociales entran en una fase de contemporaneidad el 9 de noviembre del 1989, cuando el Muro de Berlín se vino abajo y diversos alzamientos sociales y políticos en Europa del Este acabaron con sus regímenes, terminando con la caída del comunismo en la Unión Soviética, en 1991.

A partir del entonces, los movimientos sociales se moverán en un contexto neoliberal, impulsado por los Gobiernos, años antes, de Ronald Reagan en Estados Unidos y Margaret Thatcher en Reino Unido. 
La consolidación, en gran parte del mundo, de estas políticas neoliberales suponen, en primer lugar, un retroceso en las condiciones de vida de millones de ciudadanos (pérdida de poder adquisitivo, reducción de prestaciones en ámbitos como educación o sanidad, privatización de servicios básicos o un desempleo creciente), fomentados, en gran medida, por la pérdida de protagonismo de los Estados-nación en el mantenimiento de redes de protección social para sus ciudadanos.

El primer día de enero de 1994 y coincidiendo con la entrega en vigor del Tratado de Libre Comercio de América del Norte (TLCNA) entre Estados Unidos, Canadá y México, el Ejecito Zapatista de Liberación Nacional (EZLN), un pequeño grupo guerrillero de inspiración zapatista, escasamente armado, declaró la guerra al Gobierno de Carlos Salinas y a las Fuerzas Armadas mexicanas.

La guerrilla zapatista, liderada por el Subcomandante Marcos, ocupó, en el Estado de Chiapas, siete pequeñas ciudades, reclamando no sólo justicia social para un pueblo, el indígena, sino un nuevo modelo de Estado, basado en la libertad, la justicia y la democracia.

EI EZLN introdujo los movimientos sociales en el siglo XXI, desarrollando nuevas formas de organización y coordinación para el activismo, gracias a la, por entonces, casi recién nacida Internet. Los movimientos sociales, en un contexto de neoliberalismo y globalización, encontraron en la Red su aliado perfecto para generar redes de apoyo y solidaridad transnacionales.

Y si el Zapatismo, a través del EZLN, fue el primer movimiento social en emplear Internet, la primera gran manifestación en coordinarse ( $y$ organizarse) a través de la Red ha sido la popular contra-cumbre de Seattle, gran referencia para cualquier manifestación o experiencia altermundista (Hernández Millán, 2007).

Coincidiendo con la Tercera Ronda de la Organización Mundial del Comercio (OMC), a finales de 1999, en la ciudad de Seattle, al noroeste de Estados Unidos, diversos colectivos izquierdistas y de inspiración anarquista, en colaboración con algunos de los sindicatos de mayor afiliación del país, organizaron la primera manifestación coordinada por Internet, donde más de 50.000 activistas de 144 países lograron bloquear y paralizar las deliberaciones de la Cumbre, que acabó siendo un sonoro fracaso.

Estudiantes, sindicalistas, anarquistas, feministas, ecologistas, izquierdistas, religiosos, artistas.... todos unidos y ofreciendo al mundo, gracias a la Red y a una recién nacida Indymedia, una cobertura sin filtros de lo que ocurría en las calles de Seattle durante esos días, generando redes de solidaridad internacionales.

Por ello, y otros aspectos que abordaremos en esta investigación, consideramos que el Ejercito Zapatista de Liberación Nacional y la llamada "Batalla de Seattle" son dos actos 
fundacionales en el activismo online, por su uso de Internet y las nuevas tecnologías, siendo los primeros "nuevos" movimientos sociales de la Historia y espejo para futuras experiencias de movilización.

\section{Estado de la cuestión}

Para esta investigación partimos de diferentes trabajos y estudios previos sobre los movimientos (y cambios) sociales de diferentes escuelas de pensamiento, destacando la escuela europea, con autores como Alain Touraine, Claus Offe y Alberto Melucci; y la escuela americana (más bien estadounidense) con autores como Mancur Olson, Anthony Downs o el argentino Ernesto Laclau.

Según la politóloga mexicana María Ángeles Mascott, en su artículo "Cultura política y nuevos movimientos sociales en América Latina" (1997), diferencia notablemente ambas escuelas. La europea estaría interesada en los procesos de identidad (el porqué), mientras que la escuela norteamericana parece más centrada en reflexionar sobre la movilización de los activistas y/o actores sociales (es decir, el cómo).

Autores como Mayer Zald o Jean Cohen han tratado de aunar ambas tradiciones, destacando la simultaneidad, para que un movimiento social tenga éxito, de identidad y estrategia.

Sobre el Zapatismo, y el EZLN, muchos de sus estudios, artículos e investigaciones son de origen mexicano, y presentan un marcado acento nacional y/o local. Destacamos a Guiomar Rovira Sancho con "El movimiento global de resistencias y las redes" (2006) o Zapata vive. La rebelión indígena de Chiapas contada por sus protagonistas (1994), aunando el uso de Internet y las nuevas tecnologías de la comunicación con los movimientos sociales, en este caso la experiencia zapatista.

Jesús Galindo, Maite Rico o Irina Lotkova destacan por sus investigaciones sobre el EZLN, ubicándolo en el contexto local mexicano, sin olvidar la presencia de Internet en la difusión del mensaje zapatista y en su importancia en la creación de redes de solidaridad transnacionales.

De especial interés para esta investigación ha sido el Trabajo Fin de Master (TFM) de Marco Antonio Pérez Arriaga (2011), en su apartado de introducción sobre el origen de los movimientos sociales, y en las estrategias de comunicación por parte de los movimientos sociales, en especial del movimiento zapatista.

No podemos olvidar los (pocos) volúmenes de conversaciones del Subcomandante Marcos, como las mantenidas con el español Ignacio Ramonet, que nos permite conocer, de primera mano, cómo fue el levantamiento zapatista en 1994, y las difíciles 
(casi imposibles) condiciones a las que se enfrentó, además de obtener una visión fidedigna del día a día en el Estado de Chiapas.

Capitales han sido algunas obras sobre la historia de México, editadas por El Colegio de México, como los textos escritos por Guillermo Palacios (2010) o Aimer Granados y Carlos Marichal (2004), que aportan un completo contexto histótico social a la investigación y faciltan la comprensión de los acontencimientos descritos.

Con respecto a nuestra investigación sobre la contra-cumbre de Seattle, pese a la gran cantidad de artículos y textos breves sobre el tema, existen pocas investigaciones (a fondo) sobre la cuestión, destacando, en español, la tesis doctoral de Pablo Iglesias Turrión (2008), en especial los capítulos dedicados a la contra-cumbre de Seattle.

En inglés, quizá la obra más destacable sea The Battle of the Story of the Battle of Seattle (2009) de Rebecca Solnit. También han de recordarse las aportaciones del sociólogo Manuel Castells sobre la contra-cumbre en sus obras Comunicación y poder (2009) y La Sociedad Red: Una visión global (2006), en español aunque originalmente escritas en inglés.

Desde un punto de vista teórico-metodológico, es esencial la aportación de Manuel Castells en sus investigaciones sobre el espacio híbrido entre las redes de comunicación y el espacio urbano ocupado, que denomina "especio de autonomía" (Castells, 2016: 144), espacio que sirve de agrupamiento, debate y laboratorio de nuevas formas de democracia deliberativa.

\section{EZLN o la primera "ciberguerrilla" de la Historia, México (1994)}

"Me voy a hacer la revolución. A luchar contra todo lo que tú representas" Rafael Sebastián Guillén Vicente, antes del Subcomandante Marcos.

\subsection{Chiapas y el Zapatismo}

El Estado mexicano está actualmente compuesto por 32 entidades federativas, entre las que se encuentra, en el sur y lindando con Guatemala, el Estado de Chiapas. Su nombre completo es Estado Libre y Soberano de Chiapas, con una extensión superior a los 70.000 metros cuadrados, poco menos que Andalucía, y con unos índices de subdesarrollo y analfabetismo francamente alarmantes. 
Su nombre oficial no deja de ser casi una broma, pues la mayor parte de su población sufre un retraso político, económico o cultural difícilmente comparable con otras naciones iberoamericanas, incluso con indicadores inferiores a su vecina Guatemala; y su grado de autonomía y autogestión se queda en eso, en un grandilocuente nombre que nadie se toma en serio.

En 1994, la población de Chiapas era de 3.7 millones (actualmente es casi un millón más), con una tasa de desnutrición, entonces y ahora, de casi el $50 \%$. De esa población, casi un millón es indígena, de la cual un tercio apenas si habla español. Chiapas recoge el dudoso honor de ser el Estado mexicano con mayor tasa de analfabetos del país, superando el $30 \%$. La tasa de mortalidad infantil es dos veces superior a la media nacional ( $8.5 \%$ frente al $4.7 \%$ ), y el promedio de escolarización es de 4.7 años, mientras que el promedio de toda la población mexicana es de 7.7.

Pero Chiapas tuvo su primer héroe a finales del siglo XIX, un héroe que nunca llegó a pisar su suelo, pero que se convertiría en una referencia para todos los movimientos sociales que vendrían después y confluirían en un movimiento, el Zapatismo, sin el que no podemos entender la situación política del México actual.

Emiliano Zapata (1879 - 1919), que dio nombre al Zapatismo, comenzó su lucha como líder local defendiendo los derechos de los campesinos del pueblo de Anenecuilco, en Morelos, convirtiéndose en un líder revolucionario nacional con operaciones militares en los Estados de Morelos, Guerrero, Oaxaca, Puebla, Hidalgo y México. El Ejército Revolucionario del Sur, liderado por Zapata, promovió una ambiciosa reforma agraria con el nombre de Plan de Ayala, que permitía la expropiación de tierras a quienes las monopolizaban, entregándoselas a ciudadanos y pueblos de México para su gestión y explotación.

La revolución por la que luchó, y murió, Emiliano Zapata buscaba el desarrollo nacional, acabando con el sistema de haciendas y las relaciones de servidumbre, como la esclavitud o el peonaje por deudas.

El Zapatismo acabó convirtiéndose en un símbolo de lucha de clases, con un fuerte componente indígena (pues gran parte de los esclavos o peones a los que Zapata quería liberar eran, son, indígenas) y un nada disimulado carácter nacionalista. La memoria de Zapata fue, es y será la principal inspiración para los rebeldes de Chiapas, el Ejercito Zapatista de Liberación Nacional (EZLN), que luchan por sus mismos ideales: los derechos de todos los mexicanos, en especial su población indígena, casi siempre la más oprimida (Lotkova, 2001). 


\subsection{El Subcomandante Marcos o el Ejército Zapatista de Liberación Nacional (EZLN)}

A las afueras de la ciudad de Monterrey, en 1969, un grupo de estudiantes universitarios liderados por César Germán Yánez, crearon las Fuerzas de Liberación Nacional (FLN), escogiendo a Chiapas como primer foco de su incipiente guerrilla. El Estado Libre y Soberano de Chiapas reunía todas las características de la desigualdad social que entonces, y ahora, se daban en México: un territorio riquísimo en recursos naturales, donde la gente vivía en la miseria y sin ningún tipo de esperanza.

Tras algunos años de conflictos armados de escasa importancia y nula repercusión mediática, habría que esperar al 1994 cuando se uniría a la guerrilla quien cambiase no sólo su futuro, sino el porvenir de gran parte de los movimientos altermundistas del planeta: Rafael Guillén, que según las costumbres del FLN tomó el nombre de Marcos, un guerrillero muerto en combate unos años antes (Lotkova, 2001). Entonces, las Fuerzas de Liberación Nacional (FLN) pasaron a llamarse Ejercito Zapatista de Liberación Nacional (EZLN).

Rafael Guillén, ahora Subcomandante Marcos y referencia constante a lo largo de esta investigación, ha sido (es) una de las figuras más relevantes de la izquierda internacional en las últimas décadas, símbolo (como lo fue en su momento el Che Guevara) de todas aquellas minorías que, en algún momento de la Historia, han sido oprimidas: indígenas, negros, homosexuales, apátridas. El sempiterno uso de un pasamontañas negro y sus escasas apariciones públicas le transformaron (no sabemos si conscientemente) en la representación de la revolución, de la lucha contra las desigualdades, fueran donde fueran. Su imagen trascendió más allá de la Selva Lacandona, en Chiapas, para saltar a las mentes de todo el mundo como un símbolo de disconformidad y lucha, de justicia social.

Y resulta curioso, como él mismo afirmaría que "para que nos vieran, nos tapamos el rostro; para que nos nombraran, nos negamos en nombre; apostamos el presente para tener futuro; y para vivir... morimos" (Ramonet, 2007: 27).

Licenciado con honores en Filosofía y Letras y profesor en la Universidad Nacional Autónoma de México (UNAM), criollo y de familia acomodada (una de sus hermanas ocupó cargos importantes en Gobiernos del Partido Revolucionario Institucional, PRI), siempre creyó que el final del México corrupto, despiadado, racista y profundamente clasista sólo sería posible con un estallido armado. Quizá por ello fue a encontrar su destino, sin saber que inspiraría a generaciones enteras de activistas sociales, en la región más pobre de México, luchando por un Estado igualitario, proletario, autogestionado y de fuerte influencia marxista - leninista.

Sólo viviendo entre, y como un pobre, se puede ayudar a los pobres, nos dice el Evangelio de San Mateo. Y, al igual que el Evangelista, Rafael Guillén decidió recorrer 
los casi 1000 kilómetros que separan Ciudad de México con Chiapas y vivir entre los indígenas más paupérrimos del país.

Rafael Guillén decidió convertirse en el Subcomandante Marcos.

\subsection{EZLN vs Zapatismo}

Hay que distinguir al EZLN del Zapatismo, ya que la guerrilla es una organización política y militar, mientras que el Zapatismo es un movimiento político y social mucho más amplio.

Entre sus características comunes está su origen como grupo armado de autodefensa. De la misma manera que el Partido Panteras Negras en Estados Unidos surgió, en 1966, como instrumento de defensa de la comunidad negra contra los abusos de la policía, en la ciudad de Oakland, el EZLN, al igual que el Zapatismo, surge como herramienta de protección del campesino, mayoritariamente indígena, contra los abusos de los dueños de las tierras (Leyva y Sonnleitner, 2000).

La expropiación de tierras a los sectores pobres de Chiapas, gracias al decreto presidencial de 1971, unido a la reforma del artículo 27 de la Constitución, en 1991, fueron los elementos que llevaron a una politización (y militancia) extrema de grupos indígenas.

Si a ello le sumamos la implantación en América Latina del modelo neoliberal, impulsado por el Consenso de Washington, que ha provocado un grave deterioro en las condiciones de vida de gran parte de la población (altas tasas de desempleo, reducción del gasto social en sanidad y educación o una creciente pérdida de poder adquisitivo) ha formado el caldo de cultivo ideal para la consolidación del EZLN.

Este tejido social, o "sociedad red", como diría Manuel Castells (2006), es el entorno donde el EZLN busca captar de todos aquellos seguidores activos, comprometidos con su lucha, y no sólo simpatizantes, aunque estos últimos sean fundamentales para internacionalizar las intenciones de la guerrilla, a través de Internet.

En esta nueva "sociedad red", los activistas están generando nuevas formas y prácticas que permiten la creación de redes de resistencia global, con el fomento de una sociedad alternativa, más democrática y configurada globalmente en red.

EI EZLN fue parte de un movimiento de justicia global, representando el nacimiento de un proyecto político alternativo, basado en la articulación de luchas locales y globales contra una coyuntura forjada por la globalización empresarial (Castells, 2006: 420). 
La lucha universal de los oprimidos contra el neoliberalismo es, quizá, el objetivo último del EZLN, más allá del fomento de una democracia electoral real o los derechos de la minoría indígena del país.

\subsection{Crónica de una insurrección}

El primer día de enero de 1994 y coincidiendo con la entrada en vigor del Tratado de Libre Comercio de América del Norte (TLCAN), el mundo cambió. Y no por este tratado entre Canadá, Estados Unidos y México, que parecía condenar aún más, si esto es posible, a la numerosa población indígena mexicana, sino porque un pequeño ejército, escasamente armado, declaró la guerra al Gobierno de Carlos Salinas.

No sólo se reivindicaba justicia social, sino que exigía derechos civiles y políticos, como elecciones libres, una nueva Constitución que recogiese los derechos indígenas... además de un marcado carácter autonomista, más vinculado con la población indígena que con el Estado de Chiapas, es decir, derechos otorgados a una patria de personas, no de territorios.

La aplicación del Tratado de Libre Comercio es una sentencia para los pueblos indígenas de todo México (Rovira, 1994), por lo que la batalla también es contra el neoliberalismo global y las nuevas políticas capitalistas y sus consecuencias, en una sociedad cada vez más globalizada e interconectada.

Ese día, tropas zapatistas ocuparon siete pequeñas ciudades en Chiapas: San Cristóbal, Las Margaritas, Altamirano, Oxchuc, Huixtan, Canal y Ocosingo. En la primera Declaración de la Selva Lacandona, el EZLN declaró la guerra al Gobierno de Carlos Salinas y a las Fuerzas Armadas del país.

La población local de estas ciudades se unió al EZLN, y apenas si existieron enfrentamientos armados entre la guerrilla y el ejército mexicano.

EI EZLN dio un mensaje al mundo de la existencia de los indígenas en una pequeña y olvidada parte de México, colocando en el mapa una desigualdad que, poco después, la casi recién nacida Internet difundió por el mundo.

Pero el 4 de enero, los primeros días "dulces" del EZLN tocaron a su fin, con violentos enfrentamientos entre guerrilleros y militares, respondiendo a una llamada de la Secretaría de la Defensa Nacional. Aviones del ejército bombardearon posiciones de la guerrilla en las montañas de San Cristóbal de las Casas, dejando 61 muertos.

En unos días, casi 25.000 soldados ocuparon la región. El 12 de enero el presidente Carlos Salinas ordenó el alto el fuego, al ver cómo, casi en horas, Chiapas saltó a las 
primeras páginas de los periódicos y a las primeras noticias de los telediarios, no sólo del país, sino en todo el mundo.

Pocos después comenzaron las negociaciones de paz entre la guerrilla y el Gobierno, en San Cristóbal. El presidente Salinas presentó unas tímidas propuestas de mejora para la situación indígena de todo el país, que finamente fueron rechazadas por el EZLN, con la Segunda Declaración de la Selva Lacandona, donde se instaba a una Convención Nacional Democrática para redactar una nueva Constitución. Casi diez mil personas llegaron a la Selva Lacandona en agosto de 1994 para asistir a esta Convención Nacional Democrática.

El movimiento parecía ganar adeptos y crecer por todo Chiapas. En diciembre, el EZLN ocupó (¿o deberíamos decir liberó?) 38 municipios más, declarándoles autónomos y rebeldes.

En la Tercera Declaración, publicada en enero del 1995, el EZLN impulsó la creación de un Movimiento para la Liberación Nacional. Pocas semanas después, en un intento de desmitificar al principal símbolo del movimiento, el Subcomandante Marcos, el Gobierno reveló su identidad, ordenando su detención inmediata. Ese año, el ejército abandonó su política de apaciguamiento y ocupó militarmente gran parte de la Selva Lacandona y consideró al EZLN como grupo terrorista. La respuesta tuvo lugar el 25 de agosto, cuando más de un millón de mexicanos participaron en una consulta para que el EZLN se convirtiera en fuerza política.

En 1996 se firmaron los Acuerdos de San Andrés (germen de la reforma Constitucional de 2001) entre líderes del EZLN y del Gobierno Federal donde "se establecía una nueva relación entre los Pueblos Indígenas y el Estado, que termine con la relación de subordinación, desigualdad, discriminación, pobreza, explotación y exclusión política de los indígenas". Este principio de acuerdo desembocó en la Comisión legislativa de Concordia y Pacificación (COCOPA), que reconocía el derecho a la "libre determinación y autonomía". Tan ambicioso proyecto fue rechazado finalmente por el Gobierno.

En el fondo de la cuestión, se trataba del reconocimiento de unos derechos políticos de los indígenas, que debían traducirse en la capacidad de tener gobiernos propios y elegir a sus autoridades según sus tradiciones y costumbres, en un proceso de empoderamiento, aunque siempre bajo soberanía del Gobierno Federal.

El rechazo de la Comisión no frenó el impulso de la guerrilla, y casi de inmediato se pusieron en marcha los llamados Municipios Autónomos Rebeldes Zapatistas (MAREZ), bajo la protección del EZLN. Los MAREZ tienen funciones propias como educación, salud, vivienda, fomento del trabajo colaborativo, justicia o cultura. Estos municipios han funcionado a través de Consejos Autónomos Rebeldes Zapatistas, integrados por representantes que provienen del colectivo, con la obligación de reportar 
periódicamente de sus decisiones, y con su cargo constantemente a disposición del grupo en caso de mala praxis.

Los MAREZ fueron sólo el principio de la autonomía zapatista, que continuó desarrollándose con la creación de los llamadas Caracoles, así como las también conocidas Juntas de Buen Gobierno (JBG), punto de encuentro entre los miembros de la sociedad civil y las comunidades indígenas zapatistas, máximos responsables de la aplicación de la autonomía indígena.

Como señala Martínez Espinosa (2007: 23), ambas figuras "son consecuencia de dos estrategias del movimientos zapatista: 1) Construcción autónoma de recursos, medios y procesos para la subsistencia de las comunidades indígenas; y 2) Acercamientos, encuentros y contactos con quienes el EZLN Ilama "la señora sociedad civil nacional e internacional".

Pero si hay una fecha que ningún zapatista, o simpatizante, olvida, fue el 22 de diciembre de 1997, cuando 45 indígenas, casi todos mujeres y niños, fueron asesinados por un grupo paramilitar en la localidad de Acteal. Todos eran simpatizantes de los zapatistas. El mundo pareció culpar al, entonces, presidente Ernesto Zedillo, por su constante beligerancia contra el movimiento.

En 1999 tuvo lugar la mayor demostración de fuerza popular de los zapatistas, al lograr que casi tres millones de mexicanos participasen, positivamente, en una Consulta Nacional sobre la Ley de los Derechos Indígenas, lo que produjo una cierta relajación en las relaciones entre el EZLN y el Gobierno.

La enorme popularidad del EZLN entonces, junto a la elección por primera vez en 71 años de un presidente de oposición, Vicente Fox, llevó a que las Fuerzas Armadas desplegadas en Chiapas regresasen a los cuarteles y que el EZLN aceptase volver a la mesa de negociación para continuar con el diálogo.

En febrero del 2001, el EZLN comenzó una larga marcha al Distrito Federal. Rafael Guillén ya había recorrido ese camino, a la inversa, hacía casi veinte años. Ahora volvería a recorrerlo como el Subcomandante Marcos. EI EZLN pasó por algunas de las regiones con mayor porcentaje de indígenas: Oaxaca, Puebla, Veracruz o Morelos (patria de Emiliano Zapata), para acabar siendo recibido por más de 200 mil mexicanos en la plaza del Zócalo, en la capital, invitados, por primera vez en su historia, al Congreso de la Unión.

El 25 de abril, el Senado aprobó importantes reformas constitucionales en materia indígena. 


\subsection{La primera "ciberguerrilla" de la Historia}

Si hay alguien que supo definir a los guerrilleros zapatistas en su relación con las nuevas tecnologías, con Internet, fue el entonces Secretario de Relaciones Exteriores de México, José Ángel Gurría, que definió el levantamiento armado del EZLN como "una guerra de tinta e internet".

El Subcomandante Marcos, quizá mejor que cualquiera de sus compañeros guerrilleros, entendió que su revuelta, históricamente insignificante y escasa en medios materiales, no podía hacer frente al poderoso ejército mexicano sin ganarse la atención (y simpatía) del mundo, entendiendo que la prensa, la radio, los medios de comunicación masivos y, sobre todo, la Red, que en 1994, momento del levantamiento armado, acaba de cumplir un año, eran esenciales.

"En el siglo XXI las batallas no serán por conquistar espacios geográficos sino por invadir espacios cotidianos: plantar la bandera en las cimas peladas (y peliagudas) de la opinión pública. El subcomandante Marcos es, en ese sentido, precursor de las luchas de Internet, del manejo mediático" (Galindo, 1998: 1).

Imposible no recordar aquí al sociólogo Manuel Castells (2006) cuando afirma, en cualquier entrevista, que el cambio social siempre se producirá en las mentes de las personas (o no se producirá).

El EZLN es uno de los mejores ejemplos de cómo las nuevas tecnologías han cambiado los movimientos sociales, hasta el punto de llamarles, a partir de 1994, nuevos movimientos sociales.

El Zapatismo introdujo estos movimientos en el siglo XXI, insertándolos en un contexto de neoliberalismo y globalización, donde Internet juega un papel capital en la creación de redes de apoyo.

“Nunca antes una guerrilla tan débil, desde el punto de vista militar y político, recibió una atención tan gigantesca. Doce días de disparos garantizaron al Ejercito Zapatista más cobertura informativa que 30 años de guerra en Colombia" (Rico, 1999: 1).

Todo ello coincidió con el inicio del boom de internet y las nuevas tecnologías en México, inaugurando en el país, y en la Red, nuevas formas de organización y coordinación en los movimientos sociales, basadas en redes horizontales y participaciones directas, más allá de los filtros de los medios de comunicación masivos.

El conflicto armado pasó de las trincheras de la Selva Lacandona a un frente inédito: Internet.

Las primeras informaciones sobre el levantamiento zapatista que empezaron a circular por internet fueron correos electrónicos de algunos simpatizantes y/o miembros del EZLN en la pequeña ciudad de San Cristóbal de las Casas, una de las pocas en la región 
con conexión a internet. Eran mails de tipo personal, a través de foros de discusión como soc.culture.mexico. Se trataba de un foro que mezclaba todo tipo de informaciones sobre México, entre las que empezaron a aparecer noticias de lo que estaba ocurriendo en Chiapas.

Estos primeros comunicados del EZLN fueron emitidos por el Comité Clandestino Revolucionario Indígena, consciente (sin duda impulsado por el Subcomandante Marcos) del gran impacto en la opinión pública. Tener miles de "ojos virtuales" en Chiapas dificultaban una brutal, agresiva e inmediata respuesta del ejército mexicano, como varios miembros del Gobierno Federal deseaban.

Todas las informaciones sobre el levantamiento aparecían en la jornada siguiente en el periódico nacional La Jornada, o el periódico local Tiempo de San Cristóbal, para estar horas después en Internet, traducidos y difundidos por los millares de simpatizantes en cualquier parte del mundo. Su difusión fue rápida y eficaz.

Internet se había trasformado en un espacio abierto para la información e interacción de miles de personas, permitiendo obtener información actualizada, veraz y abundante, desembocando en una suerte de acción colectiva que inauguró, a nuestro juicio, el primer movimiento social moderno al facilitar que diferentes grupos sociales puedan organizarse y coordinarse en la defensa de unos intereses comunes gracias a la Red.

En México ya se encontraban, de manera muy activa, listas como Mexnews, de profesores y estudiantes universitarios, donde se debatían temas políticos, culturales y económicos del país. Poco después, por parte de algunos profesores universitarios mexicanos, apareció la lista Chiapas-L, que fue el primer foro "oficial" sobre el EZLN.

Aunque fue en Austin, Texas, cuando un estudiante universitario creo la primera web "casi oficial" de los zapatistas, con el nombre Ya Basta! (www.eznl.org), a la par que Chiapas 95, la lista más grande y completa de información sobre el levantamiento zapatista, en diferentes idiomas (inglés, español, alemán) y logrando crear un flujo de información y debate casi constante.

Miles, millones de usuarios de Internet pudieron seguir en la Red la lucha diaria de la guerrilla en Chiapas, transformando el ciberespacio en una fuente de información, difusión y solidaridad. Comparado con los medios tradicionales, como la radio o la televisión, internet permite la interactividad y la coordinación entre los usuarios, creando redes de apoyo, lo que incrementa, de manera virtuosa, la difusión (en este caso, la lucha del EZLN) y la creación de nuevas redes de solidaridad.

Al traspasar los límites estrictamente mexicanos o chiapanecos, gracias a la Red, el EZLN tomó bandera, es decir, representó a todo aquel no incluido dentro del reparto del mundo (Lotkova, 2001). Su lucha es una invitación, que gozosamente difundió 
Internet, ya no sólo a los pueblos indígenas mexicanos (o de toda Latinoamérica), sino a todo el que se encuentre bajo la hegemonía neoliberal.

EI EZLN no sólo buscaba un cambio de régimen, entendido éste como un nuevo sistema político representativo que facilite a las comunidades indígenas dirigir sus propias realidades; sino la construcción de una solidaridad plural y amplia que garantice un cambio social. Un cambio revolucionario, comenzando en Chiapas y que se extienda por toda la geografía mexicana. Pero este cambio, esta revolución, no tiene que tener un solo caudillo (quizá por ello el Subcomandante Marcos usa pasamontañas, en un intento por colectivizar su lucha). La titularidad de la revolución es colectiva, plural. La búsqueda de democracia, libertad y justicia tiene que ser una lucha de todos.

No sólo se trata de hacer partícipe a los pueblos indígenas de Chiapas en esta lucha, se trata de globalizar este tríptico de democracia, libertad y justicia a través de Internet. Los zapatistas comentaban artículos, noticias, declaraciones en una "conexión" a través de la Red que ha continuado, y que continúa hasta nuestros días.

La guerra de la información permitió una sinergia total entre zapatistas y sociedad civil, facilitando una reciprocidad entre emisores y receptores, que también se convertían en emisores... en un proceso que termina, inexorablemente, creando una red de solidaridad transnacional.

Las nuevas tecnologías de la información facilitan la movilización masiva sin que exista un cuadro permanente de militantes, es decir, Internet ha hecho posible (puesto en práctica por primera vez en esta ocasión) que personas, grupos y organizaciones, en diferentes países, puedan seguir en contacto, decidiendo su grado de implicación en el movimiento social.

\section{La Batalla de Seattle, Estados Unidos (1994)}

"Está claro que hemos subestimado su capacidad de organizar reuniones y montar protestas. Todo eso no hubiera sido posible sin Internet" James Wolfensohn, presidente del Banco Mundial (1995 - 2005). 


\subsection{9 de noviembre de 1999}

El 9 de noviembre de 1989 el mundo cambió. Para muchos, el principio de la modernidad comenzó en ese momento, cuando la noche del 9 al 10 de noviembre, el Muro de Berlín se vino abajo. Como escribe el sociólogo Greil Marcus (1989: 15) "se convirtió en un recuerdo, como los rastros de carmín, que se borran de la piel pero no de la memoria".

Pero no sólo fue el llamado "muro de la vergüenza" (Schandmauer) lo que despareció para siempre. Durante ese 1989, alzamientos políticos y sociales en Europa del Este llevaron a un derrocamiento de sus regímenes, que terminó con la caída final del comunismo en la Unión Soviética. La Guerra Fría parecía haber llegado a su fin con un claro vendedor: el capitalismo.

Francis Fukuyama (1992) anunció que habíamos llegado al "final de la Historia" y que, a partir de entonces, el mundo entero disfrutaría de su mayor periodo de paz y prosperidad, impulsado en gran medida por la introducción de políticas neoliberales gracias a los Gobiernos, años antes, de Ronald Reagan en Estados Unidos y Margaret Thatcher en Reino Unido.

Gran parte de los movimientos izquierdistas o sindicales, contestatarios en todo caso, fueron silenciados, en pro de una mejor concordia social y una cierta pátina de prosperidad y riqueza generalizada.

Pero la consolidación, en gran parte del mundo, de estas políticas neoliberales, no sólo debilitaba cada vez más el papel del Estado-nación en el bienestar de sus ciudadanos, sino que estos sufrían, día a día, un grave deterioro en sus condiciones de vida (pérdida de poder adquisitivo, desempleo creciente, nula o escasa protección medioambiental o reducción de prestaciones sociales en ámbitos como educación o sanidad).

Durante las últimas décadas, el salario no sólo era la retribución monetaria por una labor, también estaba vinculado a un conjunto de derechos, protegidos por un Estadonación preocupado por la seguridad social y por el progreso de sus ciudadanos. Con la implantación de políticas neoliberales, los Estados-nación adelgazan estas redes de protección y limitan su soberanía, con una precarización del trabajo que ninguna pátina de bienestar puede disimular.

En el 1994 ocurrieron dos hechos fundamentales, entrelazados. Primero, la aprobación del Tratado de Libre Comercio de América del Norte (TLCAN) entre Estados Unidos, Canadá y México, con grandes beneficios para corporaciones y empresas; un paso más en el proceso de liberalización económica (y pérdida de protagonismo en el papel de los Estados-nación como "protector" de sus ciudadanos). $Y$, en segundo término, el levantamiento armado del Ejercito Zapatista de Liberación Nacional (EZLN) en Chiapas, 
al sur de México. Una insurrección armada de un pequeño grupo guerrillero, históricamente insignificante y escasamente equipado, pero que, gracias a la casi recién nacida internet, se convirtió en un referente de todos los movimientos antiglobalización del planeta.

El clima de descontento fue creciendo, no sólo en México, sino en el país "promotor" del TLCAN, Estados Unidos, donde se produjeron importantes manifestaciones y huelgas durante los años 1998 y 1999 promovidas por el sindicato AFL - ClO (American Federation of Labor - Congress of Industrial Organizations), mayoritario en el país con más de 13 millones de afiliados. Desde el primer momento, este sindicato (con el apoyo de otros más pequeños como USWA, United Steelworkers of America, con casi cuatro millones de afiliados entre Estados Unidos y Canadá) rechazó la aplicación del TLCAN y miraba con profundo recelo la posible incorporación de China a la Organización Mundial de Comercio (OMC).

El anuncio que a finales de 1999 se celebraría en Seattle, Estados Unidos, la llamada "Ronda del Milenio" o Tercera Ronda de la Organización Mundial de Comercio fue la oportunidad perfecta para el estallido de todo el malestar existente ( $y$ creciente) en las clases trabajadoras.

La protesta fue organizada por D.A.N (Direct Action Network), una coalición de grupos radicales e izquierdistas, a la que se unió el colectivo británico Reclaim the Streets especialista, desde la década de los años noventa, en ocupar el espacio público con fines lúdicos y anti consumistas. Juntos crean la plataforma N30 (nombre que coincide con la fecha), además de la web y lanzar la primera convocatoria por Internet (Iglesias Turrión, 2004).

Luego se unirán estudiantes, ecologistas, activistas, sindicalistas, anarquistas, jubilados, religiosos, feministas, artistas... en la que se conoce como la primera contracumbre organizada (y coordinada) por Internet, y espejo para futuras experiencias de movilización y activismo, a nivel mundial.

Aunque la fecha escogida para el arranque oficial de esta tercera conferencia de la Organización Mundial del Comercio (OMC) fue el 29 de noviembre, durante la jornada anterior se registraron algunas protestas, como la ocupación por parte del grupo anarquista Black Bloc de un edificio abandonado en Virginia Avenue. Y aunque el inmueble fue ocupado para recibir a algunos asistentes a las protestas del día siguiente, se utilizó como símbolo para reivindicar el derecho a la vivienda en la ciudad.

Mucho se ha escrito sobre el grupo anarquista Black Bloc, y sobre su papel en la contra-cumbre de Seattle. El Black Bloc (bloque negro en español) es un grupo autónomo surgido en Alemania, en los años ochenta, de inspiración anarquista y que nació para defender las ocupaciones y enfrentarse tanto a la policía como a grupos 
nazis. Con sus rostros cubiertos por máscaras y totalmente vestidos de negro para dificultar su identificación por la policía (por ello fueron denominados Der Schwarze Block, "El bloque negro"), siempre han ofrecido protección a las ocupaciones y otro tipo de manifestaciones, además de impedir la infiltración de agentes provocadores.

Actualmente casi no se puede hablar de su presencia en Europa, pero durante la contra-cumbre de Seattle reaparecieron como grupo cuasi violento, orientado a la destrucción de la propiedad privada como forma de protesta, originando no poca controversia.

Como explica David Graeber (2014), los "bloques negros" han estado integrados tanto por anarquistas como por activistas antiautoritarios, y gran parte de su función (tanto en Seattle como en posteriores experiencias, véase Occupy Wall Street) ha sido proteger de la policía a los manifestantes más vulnerables o pintar eslóganes con espray. Cierto que muchos de los miembros de los "bloques negros" comparten una misma filosofía revolucionaria en la que no suelen tener problemas en emprender ataques simbólicos contra propiedades corporativas e incluso responder (limitadamente) los ataques de la policía.

Muchos medios de comunicación han comparado al Black Bloc con los Panteras Negras (que también nacieron como grupo de autodefensa frente a la brutalidad policial en Oakland, California), recordando que su presencia (de ambos) en manifestaciones, y en cualquier tipo de activismo, perjudica los objetivos del mismo, alejando a las comunidades de clase trabajadora o dando un pretexto a la policía para intervenir con mayor violencia.

El 29 de noviembre, la ciudad de Seattle se despertó con una pancarta gigante, colgada en una grúa de la construcción a más de 70 metros de altura, con las palabras Democracy (Democracia) y WTO (Organización Mundial de Comercio) cada una con una fecha apuntando en direcciones opuestas.

Cinco activistas de Rainforest Action Network fueron detenidos por esta acción. No serán los únicos detenidos por la policía durante la jornada. La formación de una cadena humana por la condonación de la deuda externa, en algunas de las calles más céntricas de la ciudad e inmediatamente "desarmada" por la policía de la ciudad o el reparto de productos de agricultura ecológica frente a un céntrico McDonalds (iniciativa liderada por el dirigente campesino francés José Bové) fueron algunas acciones que llevaron a un total de ocho detenidos a la cárcel durante ese día. 


\subsection{0 de noviembre de 1999}

Existe una foto popularizada de esa jornada, de una joven ecologista vestida de tortuga con un cartel que rezaba: "Turtles and teamsters together at last" ("tortugas y camioneros juntos por fin"). Unidos, sin duda y quizá por primera vez en la historia gracias a Internet, en una jornada de activismo imitando la organización en Red, es decir, descentralizada, sin líderes, asociativa y horizontal, evitando de esa manera que la policía pudiera "descabezar" el D.A.N. (Direct Action Network), principal organizador de las protestas, deteniendo a algunos de sus líderes.

Y así comienza un "Día de Acción Global" (Global Action Day) con la llegada a Seattle de miles de manifestantes al Estadio Memorial de la ciudad, para posteriormente dirigirse al hotel Sheraton, principal lugar de reunión de la OMC, para dificultar la entrada de los casi 3000 delegados.

Esta manifestación / concentración, liderada por el poderoso sindicato ALF-CIO, superó todas las expectativas, participando más de 30.000 personas, a las que se unió un numeroso grupo de activistas, en su mayoría estudiantes universitarios de todo el país, que ya estaban ocupando el centro de la ciudad desde la madrugada.

Aunque algunas fuentes, especialmente la prensa progresista, hablaron de casi 100.000 manifestantes, una cifra más aproximada y realista (Rovira Sancho, 2005) ubicó el número en 50.000 personas. Una cifra fabulosa de manifestantes de 144 países que, como vuelve a explicarnos Rovira Sancho (2001: 4), incluían:

Desde estudiantes opuestos a las maquiladoras hasta gente disfrazada de árboles en defensa de las selvas del mundo; mujeres, grupos de homosexuales, de lesbianas; anarquistas contrarios a la tecnología, luchando junto a ciberactivistas y hackers. Jóvenes de todas pintas; intelectuales caminando junto con obreros metalúrgicos; estibadores; viejos hippies, reliquias de las luchas contra la guerra de Vietnam; grupos de performance; muñecos y mantas con todo tipo de leyendas. Organizaciones de consumidores como Public Citizen. Integrantes de Médicos sin Fronteras. Grupos de rock, grupos de rap. Budistas, cristianos, ecologistas de todo tipo ("Earth first!": Primero la Tierra). Sierra Club, los sindicalistas de AFL-ClO, el Longshoresmen ("Food, not bombs": Alimentos, no bombas). Los que se oponen a las minas antipersonas, los que piden cerrar la Escuela de las Américas, los que luchan por una Birmania libre, los que denuncian a China... Unas mil 500 organizaciones no gubernamentales...

Los manifestantes, perfectamente organizados, cortaron calles estratégicas e impidieron la circulación entre los principales hoteles de la ciudad y el Teatro Paramount, donde estaba planeada la inauguración. Marlaine Barchevsky, máxima responsable comercial norteamericana y encargada del discurso de bienvenida, quedó atrapada en su hotel. Lo mismo que Kofi Annan o Madeleine Albright. 
La policía local, totalmente desbordada y sin efectivos para un número tan elevado de manifestantes, comenzó a emplear balas de goma y gases lacrimógenos. La mayoría de los activistas responden de manera pacífica, a excepción del Black Bloc (grupo de inspiración anarquista del que ya hemos hablado en esta investigación) que comienzan a romper escaparates y vidrieras de empresas multinacionales, como Nike o Starbucks, quemar contenedores o arrojar piedras y tablas de madera a los antidisturbios.

Las tácticas del Black Bloc fueron inmediatamente "empleadas" por los medios de comunicación generalistas para justificar el abuso policial y los centenares de fotografías y videos que comenzaron a circular por Internet, donde policías golpeaban y rociaban con espray pimienta a docenas de manifestantes pacíficamente sentados, sin ofrecer resistencia (La Botz, 2009).

Incluso el periódico The New York Times se unió al proceso de criminalización de los manifestantes con la publicación de un artículo (citado reiteradamente por otros periódicos y televisiones) donde se mantenía que algunos activistas (el Black Bloc, sobre todo) habían arrojado cócteles molotov a la policía. Aunque días después tuvieron que desmentir la información (incluso el Ayuntamiento de la ciudad lo hizo en una investigación posterior) quedó clara la intención de desacreditar la contra-cumbre por parte del poder económico de los Estados Unidos, que controla buena parte de los medios de comunicación del país ${ }^{1}$.

Al final de la jornada, la OMC suspende la inauguración y asume que la caótica situación de la ciudad (los gases lacrimógenos inundan el centro de Seattle y las autoridades locales se muestran incapaces de controlar la situación) impide el comienzo de las deliberaciones.

\subsection{1 de diciembre de 1999}

Con la llegada a la ciudad del presidente Bill Clinton ${ }^{2}$, y pese a las reticencias de las autoridades locales de ceder la seguridad de la Cumbre al Gobierno Federal, la Guardia Nacional y grupos SWAT Ilegaron a la ciudad. Se declararon ilegales todos los actos y marchas, y el centro de Seattle pasó a ser considerado "zona de exclusión" para cualquier manifestante, declarándose el estado de emergencia (con toque de queda a partir de las 19:00 horas) en toda la ciudad.

\footnotetext{
${ }^{1}$ CHRISTIAN, Nichole (4/06/2000) Véase < http://www.nytimes.com/2000/06/04/us/police-brace-forprotests-in-windsor-and-detroit.html> (Consultado: 20/06/2016).

${ }^{2}$ Bill Clinton, en plena campaña electoral, expresó su comprensión con los manifestantes, pero ordenó que la Guardia Nacional (y policías locales) se empleasen a fondo para recuperar la normalidad en la ciudad.
} 
Estas medidas parecieron enfurecer aún más a los manifestantes, que encontraron, a través de Internet, como gran parte de la opinión pública estadounidense apoyaba sus reivindicaciones. Sólo durante esa mañana se arrestaron más de 300 activistas. Los enfrentamientos entre manifestantes $y$ antidisturbios se recrudecieron, y pocos delegados se atrevieron a salir de sus hoteles para acudir a los actos organizados por la OMC.

Aunque el final de la Cumbre estaba programada para el viernes 3 de diciembre, pocos son lo que esperan a su clausura y varios delegados abandonan la ciudad con la convicción que la reunión ha sido un sonoro fracaso y que las diferencias entre los 135 países miembros de la OMC parecen irreconciliables. En sus taxis y limusinas, camino del aeropuerto internacional de Seattle - Tacoma, los delegados pueden leer algunas pintadas en las paredes de la ciudad: We Win (ganamos).

Aunque entonces pocos lo intuyesen (sólo el paso del tiempo permite ponderar adecuadamente este tipo de experiencias), la contra-cumbre de Seattle, que posteriormente se popularizaría como "la Batalla de Seattle", fue la mayor manifestación vivida en Estados Unidos desde las ocurridas contra la guerra de Vietnam (Sánchez Garrido, 2004).

La Ronda del Milenio concluyó sin una declaración final, y con acusaciones entre unas y otras delegaciones. Estados Unidos, con su presidente Clinton a la cabeza, acusó a los delegados europeos por los subsidios a la agricultura, mientas Europa criticó al presidente norteamericano por su demagogia y su excesivo proteccionismo a las industrias nacionales ${ }^{3}$.

Y el viernes 3 de diciembre, último día de la Cumbre, una gran manifestación de 10.000 activistas llegó a las puertas del hotel Sheraton, como despedida final de la que ha sido, a partir de entonces, la gran referencia de los movimientos sociales, del activismo anti-globalización o cualquier experiencia altermundista.

\section{Conclusiones y paralelismos}

En un primer momento, incluso antes del inicio de la Cumbre de Seattle, la información generada es tan elevada y extendida, que se pone en marcha un nuevo concepto de centro de prensa, creado por y para los manifestantes, donde cualquiera puede participar con testimonios, fotografías, vídeos e información, en un modelo que se

\footnotetext{
3 
copiará por docenas de ciudades y manifestaciones, en todo el mundo, con el nombre de Independent Media Center o Indymedia.

Aunque inicialmente se trata de un colectivo de periodistas, profesionales de la televisión y la radio, contando con el apoyo de programadores vinculados al software libre, Indymedia se "abrió" inmediatamente a cualquier activista, transformándoles en mediactivistas, aunando la protesta social con la libertad de expresión.

La idea del proyecto inicial (Fleishman, 2004: 3) fue crear "un espacio independiente, no corporativo, creado para cubrir lo que ocurre en las calles, sin editores, sin filtros y sin afiliaciones políticas".

En los días previos de la contra-cumbre de Seattle surge la preocupación de garantizar una cobertura, en los medios, que refleje los intereses de los manifestantes y, sobre todo, garantice el interés, y simpatía, de la opinión pública internacional.

Aunque el gran referente de Indymedia es la experiencia zapatista, el principal antecedente del uso de internet como herramienta de activismo, al menos en Europa, fue en la manifestación convocada el 19 de junio de 1999, en Londres, coincidiendo con la reunión del G-7 en Alemania. Esta manifestación fue organizada por el colectivo Reclaim the Streets, popular en Reino Unido por sus fiestas callejeras (o raves) como modo de protesta por la privatización del espacio público y con un marcado carácter anti-consumista.

Reclaim the Streets consideraba que los medios de comunicación generalistas ignoraban o menospreciaban sus manifestaciones, y decidieron aprovechar las posibilidades de nuevos medios, como Internet, y las nuevas tecnologías, como las pequeñas cámaras de vídeo o los primeros teléfonos móviles, para desarrollar una estrategia de comunicación autogestionada y donde los activistas pudieran convertirse en reporteros, sin filtros.

RTC contó con la colaboración de un grupo de hackers australianos y norteamericanos (Community Activist Technology - CAT) que emplearon por primera vez el software Active, que permite a los usuarios de internet la difusión de imágenes, audio y contenidos en una misma web y a tiempo real, facilitando de esta manera una cobertura colectiva de la manifestación.

Conscientes de la importancia de ganarse el apoyo de la opinión pública (y siguiendo el ejemplo del movimiento zapatista en Chiapas), Indymedia "salta" el control (y desinformación) de los medios de comunicación generalistas y promueve una información veraz y directa de lo que está ocurriendo, transformando a todo participante en la contra-cumbre en fuente de información. 
Los activistas de Seattle, quizá superando al EZLN, comprendieron que Internet es el espacio perfecto para expresar e informar sin mediación o control gubernamental, rompiendo el cerco mediático de los medios corporativos y dando a conocer lo que ocurre en las calles (como, en este caso, los abusos policiales durante las protestas). Además, fomenta la creación de redes de solidaridad, influyendo en la conciencia de los individuos y naciones.

Los activistas, estén donde estén y aliados con las nuevas tecnologías, se convierten en reporteros, capaces de usar la Red para difundir sus experiencias y testimonios en cualquier punto del mundo. Son cientos de activistas, cámara en mano, quienes informaron de la contra-cumbre de Seattle.

Seattle introdujo en los nuevos movimientos sociales la oportunidad de que naciones, regiones, clases o grupos subordinados se organicen transnacionalmente en defensa de intereses comunes (Jara y Lago Martínez, 2001).

Sin internet nada de esto habría sido posible. Las protestas contra la Ronda del Milenio fueron la primera gran ocasión en la que un movimiento, de una manera visible, se pudo organizar, coordinar y llegar a ser global a través de las nuevas tecnologías de la información, siguiendo el ejemplo del movimiento zapatista en México, y marcando un hito en el activismo online.

La creación de Indymedia impulsó (e impulsa en el presente) la creatividad de todos sus miembros, rompiendo la tiranía de las grandes corporaciones mediáticas, permitiendo que cualquier usuario pudiera subir en Internet cualquier contenido, así como comentar (y compartir) las historias, imágenes, videos y opiniones de otros activistas.

\section{Referencias bibliográficas}

CASTELLS, M. (2006): La Sociedad Red: Una visión global. Madrid, Alianza.

CASTELLS, M. (2009): Comunicación y poder. Madrid, Alianza.

CASTELLS, M. (2016): De la crisis económica a la crisis política. Barcelona, La Vanguardia Ediciones.

FLEISCHMAN, L. (2004): "Los nuevos medios de activismo: consideraciones en torno de la publicación abierta en Indymedia”. Revista Razón y Palabra, vol. 49. México.

FUKUYAMA, F. (1992): El fin de la Historia y el último hombre. Barcelona, Planeta. 
GALINDO, J. (1998): “Comunidad Virtual y Cibercultura. El Caso del EZLN en México" (en RED) <http://www.razonypalabra.org.mx/anteriores/n10/galindo3.htm> (Consultado: 21 / 02 /2016).

GRAEBER, D. (2014): Somos el 99 \%. Madrid, Capitán Swing.

GRANADOS, A. Y MARICHAL, C. (2004): Construccion de las identidades latinoamericanas: Ensayo de historia intelectual siglos XIX y XX. México, Colegio de México - COLMEX.

HERNANDEZ MILLÁN, A. (2007): EZLN: Revolución para la revolución. Madrid, Editorial Popular.

IGLESIAS TURRIÓN, P. (2004): "Los movimientos globales de Seattle a Praga". VIII Congreso de la Federación española de Sociología. Alicante, España.

(2008): Multitud y acción colectiva postnacional Un estudio comparado de los desobedientes: De Italia a Madrid (2000 - 2005). (Tesis Doctoral). Universidad Complutense de Madrid, Madrid.

JARA, A. y LAGO MARTÍNEZ, S. (2001): "Nuevos interrogantes sobre los movimientos sociales antiglobalización: de Seattle a Porto Alegre". Conferencia Regional para América Latina y el Caribe. Isla Margarita, Venezuela.

LA BOTZ, D. (2009): "De la "Batalla de Seattle" a la crisis del 2008 y Obama". Revista Viento Sur, 107 / Diciembre 2009. Madrid, España.

LEYVA, X. y SONNLEITNER, W. (2000): “¿Qué es el neozapatismo?”. Revista Espiral, 17. Vol. VI, enero - abril, Universidad de Guadalajara, México.

LOTKOVA, I. (2001): La ciberguerrilla zapatista: análisis del uso de internet para la difusión del movimiento zapatista. (Tesis Doctoral). Universidad Autónoma de Nuevo León, Monterrey.

MARCUS, G. (1989): Lipstick Traces: A Secret History of the Twentieth Century. UK, Belknap Press.

MARTÍNEZ ESPINOSA, M. (2007): “Derechos indígenas en América Latina. Emergencia política, autonomía y zapatismo". Temas y Debates, 13.

MASCOT SÁNCHEZ, M. (1997): “Cultura Política y nuevos movimientos sociales en América Latina". Metapolítica. Número, 2 / Abril - junio, 1997. Puebla, México.

PALACIOS, G. (2010): Ensayos sobre la nueva historia politica de América Latina, siglo XIX. México, Colegio de México - COLMEX. 
PÉREZ ARRIAGA, M. (2011): El papel de internet en los movimientos sociales como generador de sus redes de apoyo. (Trabajo Fin de Máster). Universidad Internacional de Andalucía, Sevilla.

RAMONET, I. (2007): Marcos, la dignidad rebelde: Conversaciones con Ignacio Ramonet. Buenos Aires, Argentina, Capital Intelectual.

RICO, M. (1999): "El Conflicto de Chiapas y los medios" (en RED) <http://archivo.estepais.com/inicio/historicos/100/7_ensayo_conflicto.pdf> (Consultado: 21 / 02 /2016).

ROVIRA SANCHO, G. (1994): Zapata vive. La rebelión indígena de Chiapas contada por sus protagonistas. Barcelona, Virus.

(2001). "Todo comenzó en Seattle" (en RED) <https://www.rebelion.org/hemeroteca/sociales/todo_seattle070101.htm> (Consultado: 16/01/2016).

(2005): “El Zapatismo y la Red Transnacional". Razón y Palabra, 47.

(2006): "El movimiento global de resistencias y las redes". Democracia, comunicación y sujetos de la política en América Latina contemporánea, 17: 161 189.

SÁNCHEZ GARRIDO, T. (2004): "El movimiento social altermundista. La nueva praxis de la acción política". Revista El Cotidiano, vol. 20 número 126 / 2004. México.

SOLNIT, R. (2009): The Battle of the Story of the Battle of Seattle. California, AK Press. 